\title{
INTEGRATION OF DESIGN AND TECHNOLOGY
}

\author{
MIKE AUSTIN \\ School of Architecture and Landscape Architecture \\ Unitec, New Zealand \\ Te Whare Waananga o Wairaka \\ Carrington Road, Mt Albert \\ Private bag 92025, Auckland Mail Centre, Auckland 1142, New Zealand \\ maustin@unitec.ac.nz
}

\begin{abstract}
Certification Boards visiting architecture schools regularly demand more 'technology' in the curriculum, and an increased 'integration' of design and technology in the teaching programme. The persistence of this over many years, despite substantial changes in what is meant by technology, suggests that it is not easily achieved, or by any means a straightforward matter. Their reference is to building technology which now needs to be distinguished from information technology where students are often more competent than their elders.

Building technology is seldom theorised (with a few notable exceptions) by either design theorists or those who teach technology. Even so called hi-tech architecture (which uses marine technology aesthetically rather than technically) is not theorised.

It is sometimes assumed that everything taught in an architecture school should be useful or necessary for a competent architect. Each subject claims this status, but this essential knowledge already crowds the curriculum. The level of understanding demonstrated by the students nevertheless appears to be minimal when compared with their precocious design abilities.

It is proposed that integration with design of half-understood technologies is too much to ask of any student during, or even after, five years of study. This paper starts to unravel some aspects of the teaching of technology and discusses issues around the notion of integration.
\end{abstract}

Keywords: Technology, integration, education. 
Every architect knows that technical issues are crucial in practice, where they act as a stimulus, constraint and directive for design. The importance of technology in architecture is unquestioned, but its role in the teaching of design (itself a contentious subject) is another matter. I have had the privilege of teaching with David Green of Archigram, an exceptional architect and teacher (as recognised by his RIBA award) and who has always been fascinated by technology. He has talked about the difficulty of being challenged by external examiners, in their demands for an increased technological component to the course and the request for the 'integration' of design and technology. The repeated persistence of this demand over many years by Visiting Boards suggests that this is not easily achieved. Further, this leads to the question of why this demand remains unchallenged.

Charles Walker has conducted (unpublished) research into the roles of Visiting Boards. He informs me that the Boards feel they are making a most useful contribution to the schools, while the schools in turn resent the enormously time-wasting bureaucratic processes and report writing involved. The Board members generally are senior practitioners (seldom technologists) with substantial experience to offer, but the visit does not contribute to the teaching in the schools. Further the students are often only marginally aware of the process. Walker claims that what the members of the boards are looking for is what they perceive as 'buildability' in student designs. That is the designs must look as though they could be built. He claims that more sophisticated and less visible consideration of technology, such as environmental control systems, are often ignored. This concern might be interpreted as with the consideration of tectonics and with the aesthetics of technology (for which there is substantial precedent) rather than the seamless integration into design. Paradoxically the integration has to be demonstrated by being articulated.Integration has been challenged by Tafuri who proposed instead "a systematic control of the links between production and information, with an entire program for reintegrating communications and technology" (Tafuri, 396-397). Integration can be seen as an attempt to control and command. There used to be talk of integration of studio with theory, but then theory branched out on its own (for a while at least) and sailed under its own steam and became its own justification. The call for integration is a call to gather such errant children back into the fold as one by one they leave the protective umbrella of the master. The call to integrate technology could be regarded as an attempt to get it under control.Demands for integration often reveal themselves as a will to power. "In 1983, a group of seven full-time members of the academic staff at the Auckland University School of Architecture came together to form a subschool within the School, which they called the 'Integrated Design Sub-school" (Ward and Hunt, 34). This became known for its involvement in a local political debate rather than for any of the designs produced - or for that matter the technology involved. This "radical departure" did not continue and has not been evaluated.It is necessary to be careful about the conventional wisdoms concerning technology. Many of the vaunted technological changes of the last century have been improvements and refinements rather than a re-thinking of technology. The piston engine universally used for transportation is over a century old and the railway is even older. Even aeronautical technology has not changed substantially in the last half century. Building technology has been notoriously archaic.Further what is meant by technology in architecture has changed, in that we now have to distinguish building technology from electronic technology. Certainly there is little reluctance by students to involve themselves with information technology and the revolution that has occurred in this area seems to have happened without an excess of comment. ANY magazine attempted an online discussion about "the mechanical in the electronic era" over 10 years ago but typically the technology let it down (ANY). Visiting Boards consist of experienced architects who are generally less competent with digital technology than the students, an issue seldom noted except by Burry has pointed out: "With the insurgency of new digital design tools to the design studio, new pressures and often irreconcilable differences have produced, in many cases, and unbridgeable gulf between the fuddy-duddies, whose currency is the sagacity born from experience, and a generation of digitally adept schoolleavers, who not only have to assimilate the priorities associated with a traditional way of practising that increasingly becomes irrelevant, but are also in the key position to point towards new ways of operating without the benefit of any meaningful apprenticeship in as yet untried modes of practice" (Burry, 32).The fuddy-duddies are not necessarily in touch with the latest building technology either, otherwise presumably there would be no need for CPD. Conditions of production and construction are changing rapidly with the use of information technology and the close association with design becomes an increasingly possible daily reality. Recently in a furniture design studio run by Jeremy Treadwell at the School of Architecture and Landscape Architecture at Unitec New Zealand, the most successful design utilised a shuffling back and forth of files between a laser cutter and model both utilising computer technology. This might be seen as a connection, or even a separation, rather than an integration, between design and 
technology, with the computer file as the medium of exchange.If technology is a misnomer for buildability and some of what is taught as technology, is current codes of practice, it is, by definition, instantly obsolete. As global practice becomes more common, local codes and practices become less and less relevant. It is often said that architects tend to be stuck with what they were taught in architecture school, which makes what they do learn even more crucial. It certainly seems that many teachers of the technologies are frustrated with the level at which they teach their subject to an unappreciative bunch of students. One way to change this is to make the teaching of technologies into building science, but it is not clear what the theoretical base of such techno-science is. Some would say it is pseudo-science when it is claimed that what is being taught are the underlying principles, because science itself is endlessly revising, reviewing and contradicting its principles. Are not these so-called principles more rules of thumb? Design theory once claimed that it was teaching basic principles, but then it theorised the problems with the idea of basic principles and abandoned the idea. It has been suggested that changes in the teaching structures "are analogous to those in teaching architectural history with the presentation of specific information being supplanted or augmented with the discussion of general theory" (Smith, 6).Design teachers do not discuss building technology at a theoretical level either. This suggests that the accusations of the technology teachers have more than a grain of truth when they accuse the studio staff of playing down technology. What is more, design staff tend to patronise the technologists because they are suspicious of them teaching design. Yet when the technologists act as consultants they are slaves to student ignorance. It seems an impossible bind, in which technology is resisted by both students and staff - as indeed the technologists seem to have been have been saying for a long time.The assumption of the staff (along with the members of the Boards) is that technical know how will improve design. This is an article of faith with all of us, but it is not self evidently true. The students have no evidence for it and some behaviour suggests otherwise. How many of us have been in studio marking sessions where the technologists point out that our top graded student gives no indication of technological awareness while bottom marks have been given to a student who has fulfilled all the technological requirements as neatly laid out by the program?Senior students often win competitions against practicing architects who also use recent graduates as their designers - while complaining loudly about their technical ignorance. It seems that students often see technical issues as some kind of a diversion from design however many times we tell them otherwise. Experienced technologists are necessary in the office and on the building site, but they don't win competitions or get validated in architecture schools. This is confirmed by the experience of design technologists when they come to architecture school to upgrade their qualifications, and find (initially at least) that all of their experience and talent doesn't necessarily produce the top graded design. The students also know that their heroes (or rather the heroes we have taught them to respect, such as Koolass, Hadid, Gehry) produce work that makes demands on technology, rather than the other way around.Pompidou (1971 Piano and Rogers) made a fetish of the technological systems, but it can be argued that they had been led to that position by Archigram who forged an architectural language out of the technologies invented by Buckminster Fuller. They combined the impossible idea of an architecture that moves with the theories of Reyner Banham who described them as "designing for pleasure, doing your own thing with the conviction that comes from the uninhibited exercise of creative talent braced by ruthless self-criticism" (Sadler 196). Tafuri had described Archigram as: "celebrations of formlessness [which] take place under the banner of technological utopia" (Sadler 195). Lloyds and the Hong Kong bank continued the fetishing of technology and it could be argued that much so called 'hi-tech' architecture has been concerned with the articulation and the aesthetization of obsolete technology. For instance many of the details of marine technology used (e.g. wire rigging and tensioning devices) are the very things that marine technologists work hard at eliminating - following the lead of aircraft technology. However while the designs are driven by the technology they are an expression rather than an integration of technology. Technologically driven architecture has always been designed by engineers, from the Crystal palace to cars, trains and airplanes. But what is strange from this is that the technologically driven is also concerned with the poetic. In the schools however as Vesely says: "How much do we need to be informed, and what and how much should we know as architects and designers? Current education is mainly oriented towards technical subjects, and yet most of these subjects are already firmly in the hands of engineers who are usually better qualified and equipped for the task. There is no doubt that architects should be at home in that field, but they don't have to emulate the work of engineers or claim to be technological experts"(Vesely 65-66).In the schools technology is also subjugated to design. This disallows technology an independence, a theory, a world of learning. The dominance of design is of course encouraged by design staff, and technologists play along with the best will in the world. The technology subjects are seen as support subjects and, like all servants, they are always 'a 
problem'. Smith says "If a subject is not presented on its own terms, for its own purpose, such as should occur in a quality liberal arts program, but rather is introduced specifically as background for another area, it is my conviction that it is best to incorporate the presentation of the principles of that subject as an integral part of the other area rather than as some separate, prerequisite" (Smith 6). Then subjects would be selected by the student's area of interest from theory, to structure, or sustainability, with each subject self sufficient with its own theoretical and disciplinary base.It seems that the desire to retain 'the architect's rightful position as head of the building team' goes against the very spirit of technology, which is anonymous and produced by acephalous teams. Yet architecture schools don't use teams much - for which the usual explanation given is the problems of assessment of the individual contributions. But there is also the question of disciplinary base, where in order to be inter-disciplinary you have to know your discipline. Arup's deputy chairman talks about working with Daniel Libeskind. "We exchanged metaphors. If the form were closed it could be a mineral deposit, or if an open transparent steel-framed building, it could be a lantern or beacon. If it were heavy it could be hacked out of granite, or was it buildable out of special masonry" (Campbell, 26). The fantasy of integration is that of being able to totally shape the world and is of course the kind of dream that drives architects. (To have everything in the 'architects 'purvue' as is said in the invitation to this conference). However this may no longer be possible. The difficulty is that there are so many important issues to be integrated with everything on the curriculum claiming utility as its justification. Usefulness as a criterion for inclusion has led in the past to the neglect of important academic areas. It may be that technology can only be taught at a theoretical level in Architecture schools. It has long been argued that architecture is not building, but about building. In this sense the Boards are looking for evidence that the students know about building rather than concerned with what they know.

\section{References}

ANY (Architecture New York), No 10,1995.

Burry, Mark, 'Homo Faber', Architectural Design, Vol 75, No 4, July/August 2005 30-37.

Campbell, Peter, 'The Way of the Wobble', reviewing Ove Arup: Master builder of the $20^{\text {th }}$ Century. London Review of Books , 5 April 2007, 26.

Sadler, Peter, Archigram: Architecture without Architecture, Cambridge, Mass, MIT Press, 2005.

Smith, David Lee Smith, 'Integrating Technology Into the Architectural Curriculum,' Journal of Architectural Education, Fall, 1987, 41/1

Tafuri, Manfredo, 'Design and Technological Utopia', Italy: The New Domestic Landscape, Achievements and Problems of Italian Design, Emilio Ambasz, (ed), New York Museum of Modern Art, 388-404.

Vesely, Dalibor, AD Vol 74, NO 5, Sept/Oct 2004, 65-66

Ward, Anthony and John Hunt, ' The Alternative Aotea Center Project, Auckland New Zealand,' Journal of Architectural Education, Fall 1987, 41/1. 